\title{
Supplemental Antibiotic Injections into the Disc Eradicate Lumbar Pyogenic Spondylodiscitis and Reduce Residual Lumbago
}

Motohide Shibayama*, Guang Hua Li, Kenzo Shimizu, Yasushi Miura, Shu Nakamura, Minoru Yamada, Zenya Ito and Fujio Ito

Aichi Spine Hospital, Inuyama, Aichi, Japan

*Corresponding author: Motohide Shibayama, Aichi Spine Hospital, Inuyama, Aichi, Japan, Tel: 81568209100; Fax: 81568209107; E-mail: moto@itoortho.or.jp

Rec Date: December 28, 2017; Acc Date: January 16, 2018; Pub Date: January 20, 2018

Copyright: @ 2018 Shibayama M, et al. This is an open-access article distributed under the terms of the creative commons attribution license, which permits unrestricted use, distribution, and reproduction in any medium, provided the original author and source are credited.

\begin{abstract}
The standard treatment for lumbar pyogenic spondylodiscitis is an intravenous antibiotic. If conservative treatment fails, surgery is indicated. However, many patients suffer from residual lumbago after prolonged conservative treatment, and invasive surgery is problematic in poorly conditioned patients. We developed a new treatment in which intravenous antibiotics are supplemented by multiple injections of antibiotic directly into the infected disc. Here we report our experience with twenty adult patients. Shortly after infection was diagnosed, we performed the needle biopsy that we reported followed by direct antibiotic injection into the infected disc. Antibiotic was injected twice weekly until inflammation subsided. The average number of injections was 6.8 . Infection was eradicated in all cases. Surgery was needed in two cases (10\%): one because of acute paralysis and one because of residual sciatica. We observed no adverse effects. Excluding two cases who died of cancer, we obtained excellent $(n=12)$ or good $(n=3)$ results $(83 \%)$ in a total of 18 patients evaluated according to Macnab's lumbago criteria at an average of 27.5 months follow-up. The disc height was retained in ten cases during the initial two months of treatment: nine of these patients showed excellent results on Macnab's lumbago scale. We conclude that supplementing standard systemic antibiotic therapy with multiple injections of antibiotic directly into the infected disc provides a safe and effective method of eradicating lumbar pyogenic spondylodiscitis. This treatment also provides an excellent chance of maintaining the disc height, which leads to less residual lumbago.
\end{abstract}

Keywords: Lumbar pyogenic spondylodiscitis; Antibiotic; Lumbago; Injection; Disc

\section{Introduction}

Lumbar pyogenic spondylodiscitis is a serious condition. Many patients are elderly or immuno-suppressed, and associated medical illnesses are frequent. The standard treatment is intravenous (IV) antibiotic with external immobilization of the spine. If conservative treatment fails, surgical intervention is indicated. The standard surgical technique combines anterior debridement with bone grafting and poses great risks for debilitated patients. Prolonged conservative treatment is also associated with a high incidence of residual lumbago. We have therefore introduced a new treatment: early biopsy with a $21 \mathrm{G}$ needle [1] followed by supplemental direct injections of antibiotic into the infected disc. We repeat the direct injections multiple times, usually twice weekly, and also administer the same antibiotic intravenously. Here we report 20 cases in which we have applied this treatment. The purpose of this study is to evaluate the efficacy of direct injection therapy for lumbar pyogenic spondylodiscitis in (1) eradicating infection, (2) retaining disc height and (3) reducing residual lumbago.

\section{Illustrative Case}

A 60-year-old man developed severe back pain and high grade fever. He presented to our hospital five days after onset of symptoms. His white blood cell count was 13,000 and CRP was 30.9. He was under insulin therapy for type 2 diabetes. Radiographs and MRI revealed disc infection at L4/5 disc and abscess in the right psoas muscle (Figures 1 and 2).

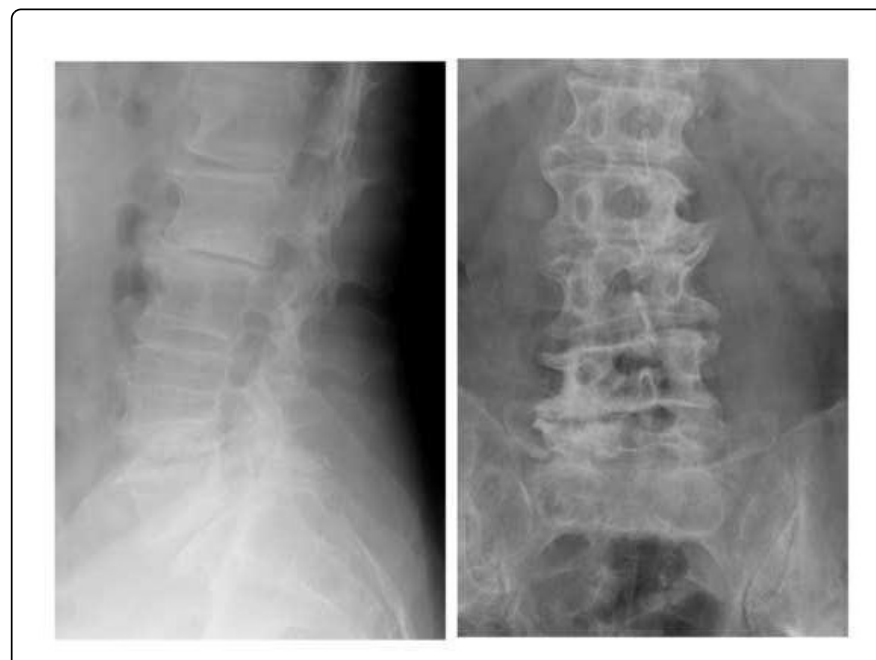

Figure 1: Radiograph 1a: lateral and 1b: A-P at presentation showing no apparent change at $\mathrm{L} 4 / 5$ disc.

At the third day after presentation, in addition to systematic antibiotic therapy, a $21-\mathrm{G}$ needle was inserted into the $\mathrm{L} 4 / 5$ disc as for discography (Figure 3).

Fluid was taken from the disc for culture. After pus aspiration and irrigation with saline antibiotic was injected into the disc. MSSA was positive for both blood culture and needle biopsy. 
Citation: Shibayama M, Li GH, Shimizu K, Miura Y, Shu N, et al. (2018) Supplemental Antibiotic Injections into the Disc Eradicate Lumbar Pyogenic Spondylodiscitis and Reduce Residual Lumbago. J Spine 7: 406. doi:10.4172/2165-7939.1000406

Page 2 of 7

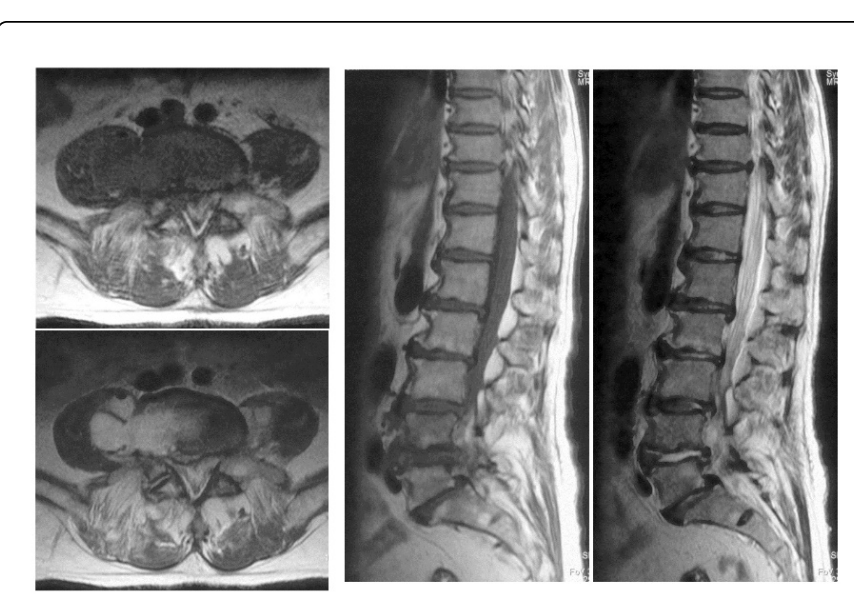

Figure 2: MRI at presentation 2a: T1 weighted, 2b: T2 weighted Axial MR scans showing abscess in the right psoas muscle, 2c: T1 weighted, 2d: T2 weighted Sagittal MR scans showing L4/5 disc is a main infection focus.

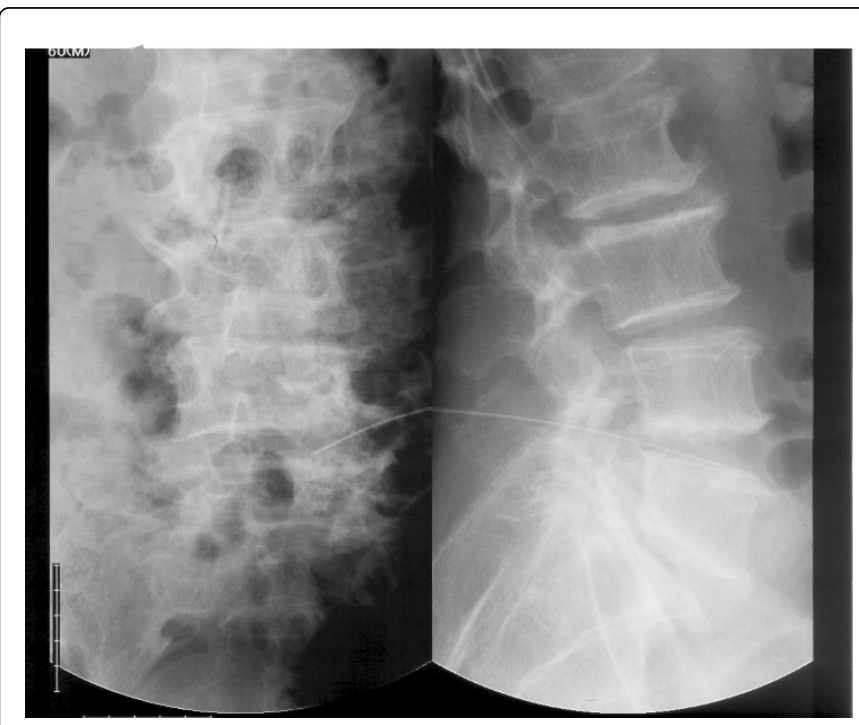

Figure 3: Disc was irrigated with saline and antibiotic was injected through a $21 \mathrm{G}$ needle as for discography.

We applied irrigation and supplemental antibiotic injection into the L4/5 disc eight times in 1 -month period. The abscess in the psoas muscle was also irrigated through a $21-G$ needle and antibiotic injected. IV antibiotic was administered for 33 days. Infection eradicated, and his back pain disappeared. The result for low back pain was excellent according to Macnab's grading at a 24-month follow-up. Radiograph showed that the height of L4/5 disc was maintained (Figure 4).

\section{Patients and Methods}

Between March 2004 and December 2014, we encountered and treated 20 cases of lumbar pyogenic spondylodiscitis. There were fourteen men and six women with a mean age of 68.0 (23 to 82). Diagnosis was based on history, elevation of C-reactive protein (CRP), white blood cell counts (WBC) and image studies including X-ray and MRI.
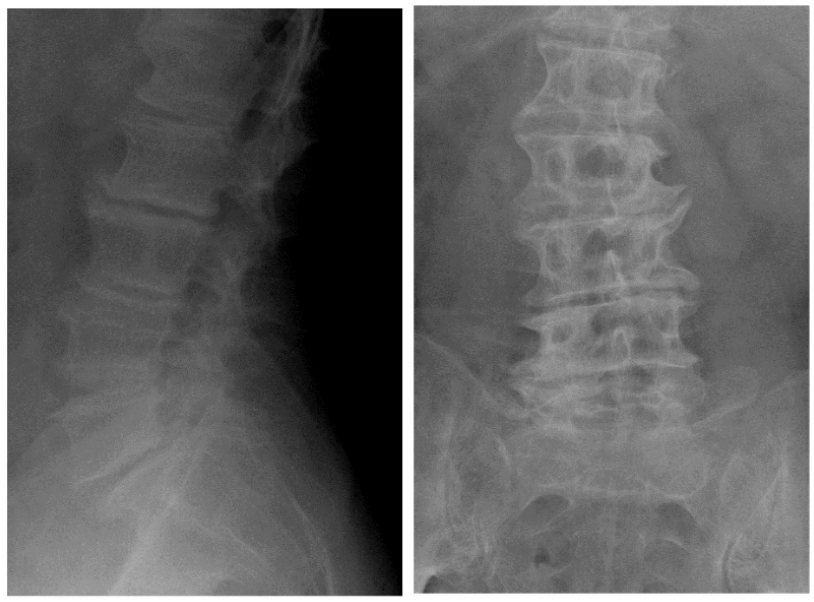

Figure 4: Radiograph 4a: lateral and 4b: A-P two years after treatment showing L4/5 Disc height was maintained.

Eight patients had been referred from other practices or departments, and eight had already been treated with IV antibiotic. The time between onset of symptoms and presentation to our department was 19.0 (3 to 64) days. The general condition of the patients was evaluated by the grading system of the American Society of Anesthesiologists (ASA). Two patients had cancer surgery within two weeks of symptom onset. There was no septic patient at presentation. Table 1 lists the medical comorbidities and other information about the patients. All patients but two, who died of cancer, were followed for at least six months (Ave. 27.5 months, 4 to $50)$.

The final outcome for residual lumbago was evaluated by Macnab's pain grading [2]. The disc height was measured on plain lateral X-ray or sagittal MR image. The levels of infection were $\mathrm{L} 1 / 2(\mathrm{~N}=2), \mathrm{L} 2 / 3$ $(\mathrm{N}=3), \mathrm{L} 3 / 4 \quad(\mathrm{~N}=3), \mathrm{L} 4 / 5 \quad(\mathrm{~N}=10)$ and $\mathrm{L} 5 / \mathrm{S} 1 \quad(\mathrm{~N}=2)$. Four cases sustained multi-level disc lesions; the most severely damaged disc was chosen for disc height measurement. There were three cases with endplate destruction on X-ray. Two cases showed segmental kyphosis, which may not be related to infection. The height was classified into A: normal height, B: half normal height or greater, C: less than half normal height, $\mathrm{D}$ : partial collision of the vertebrae and $\mathrm{E}$ : disappearance. The $\mathrm{X}$-ray was taken at initial presentation, and again at two and six months, and at one, two, and three years later, as possible.

\section{Treatment}

Under fluoroscopy the patients were placed in the lateral or prone position, as for discography. At the first treatment a needle biopsy with a $21 \mathrm{G}$ needle was performed, as we reported [1], to isolate the causative microorganism. This needle biopsy technique consists of three parts. (A) Insert a $21 \mathrm{G}$ needle as for discography, aspirate pus or fluid. (B) If step A fails, inject saline and collect fluid as reflux. (C) If step B fails, insert another needle into the disc, inject saline and collect reflux from another needle. 
Citation: Shibayama M, Li GH, Shimizu K, Miura Y, Shu N, et al. (2018) Supplemental Antibiotic Injections into the Disc Eradicate Lumbar Pyogenic Spondylodiscitis and Reduce Residual Lumbago. J Spine 7: 406. doi:10.4172/2165-7939.1000406

Page 3 of 7

\begin{tabular}{|c|c|c|c|c|c|c|c|c|c|c|c|c|}
\hline Patient & Age & Sex & $\begin{array}{l}\text { Onset to } \\
\text { Diagnosis } \\
\text { (days) }\end{array}$ & Level & $\begin{array}{l}\text { Associated } \\
\text { medical illness }\end{array}$ & ASA & $\begin{array}{l}\text { WBC } \\
\text { (x1000) }\end{array}$ & $\begin{array}{l}\text { CRP } \\
\text { (mg/dL) }\end{array}$ & $\begin{array}{l}\text { Needle } \\
\text { biopy }\end{array}$ & $\begin{array}{l}\text { Blood } \\
\text { culture }\end{array}$ & $\begin{array}{l}\text { Organism } \\
\text { isolated }\end{array}$ & Abscess \\
\hline 1 & 79 & $\mathrm{~F}$ & 28 & $\llcorner 4 / 5$ & Pyelonephritis & 3 & 15.7 & 11.5 & N/A & N/A & Escherichia coli & Psoas \\
\hline 2 & 68 & $M$ & 46 & $\llcorner 4 / 5$ & $\begin{array}{l}\text { Previous lumbar } \\
\text { surgery }\end{array}$ & 1 & 12.2 & 6.9 & $\mathrm{~N} / \mathrm{A}$ & N/A & Unknown & none \\
\hline 3 & 60 & M & 3 & $\llcorner 4 / 5$ & $\begin{array}{l}\text { Diabetes Mellitus, } \\
\text { Femoral head } \\
\text { necrosis }\end{array}$ & 2 & 13.0 & 34.5 & $P$ & $P$ & MSSA & Psoas \\
\hline 4 & 73 & $M$ & 46 & $\mathrm{~L} 3 / 4$ & $\begin{array}{l}\text { Acute myocardial } \\
\text { Infarction, } \\
\text { Colon Cancer }\end{array}$ & 4 & 13.5 & 16.1 & $P$ & N & MSSA & Psoas \\
\hline 5 & 61 & $\mathrm{~F}$ & 64 & $\mathrm{~L} 2 / 3$ & $\begin{array}{l}\text { Poor nutrition, } \\
\text { Epilepsy }\end{array}$ & 2 & 12.8 & 17.6 & $\mathrm{P}$ & $\mathrm{N}$ & Hafnia & none \\
\hline 6 & 78 & M & 7 & L4/5 & Diabetes Mellitus & 2 & 7.9 & 14.3 & $\mathrm{P}$ & $\mathrm{N}$ & $\begin{array}{l}\text { Corynebacteriu } \\
m\end{array}$ & Psoas \\
\hline 7 & 82 & $\mathrm{~F}$ & 9 & $\mathrm{~L} 3 / 4 / 5$ & & 2 & 22.2 & 32.0 & $\mathrm{P}$ & N & S. epidermidis & Psoas \\
\hline 8 & 83 & $\mathrm{~F}$ & 30 & $\mathrm{~L} 2 / 3$ & Bladder Cancer & 4 & 14.5 & 16.9 & $P$ & $P$ & MRSA & Epidural \\
\hline 9 & 66 & M & 6 & $\mathrm{~L} 4 / 5$ & Liver cirrhosis & 3 & 15.8 & 9.8 & $\mathrm{P}$ & $\mathrm{P}$ & $\begin{array}{l}\text { Klebsiela } \\
\text { pneumoniae }\end{array}$ & none \\
\hline 10 & 23 & M & 14 & L5/S & $\begin{array}{l}\text { Obesity (BMI=39), } \\
\text { Atopic dermatitis }\end{array}$ & 1 & 13.0 & 5.0 & $\mathrm{P}$ & $\mathrm{P}$ & MSSA & Epidural \\
\hline 11 & 67 & $M$ & 10 & L5/S, L3/4 & $\begin{array}{l}\text { Hepatocellular } \\
\text { carcinoma }\end{array}$ & 4 & 12.3 & 12.3 & $\mathrm{P}$ & N & S. oralis & none \\
\hline 12 & 53 & $M$ & 3 & L5/S & $\begin{array}{l}\text { Acute myocardial } \\
\text { infarction }\end{array}$ & 4 & 6.8 & 5.6 & $P$ & $P$ & MRSA & none \\
\hline 13 & 62 & M & 3 & $\mathrm{~L} 1 / 2$ & & 1 & 12.6 & 1.8 & $P$ & N & $\begin{array}{l}\text { Preptost } \\
\text { reptococcus }\end{array}$ & none \\
\hline 14 & 82 & M & 4 & $\mathrm{~L} 2 / 3$ & & 2 & 6.7 & 1.8 & $\mathrm{~N}$ & N & Unkown & none \\
\hline 15 & 79 & $\mathrm{~F}$ & 14 & $\mathrm{~L} 3 / 4$ & $\begin{array}{l}\text { Colon Cancer, } \\
\text { Pyelonephritis }\end{array}$ & 3 & 17.7 & 33.8 & $\mathrm{~N}$ & $P$ & Strptococcus B & Psoas \\
\hline 16 & 55 & M & 7 & $\mathrm{~L} 1 / 2 / 3$ & $\begin{array}{l}\text { Obesity (BMI=42), } \\
\text { Diabetes Mellitus }\end{array}$ & 2 & 16.8 & 34.8 & N/A & N/A & Strptococcus B & $\begin{array}{l}\text { Epidural, } \\
\text { Psoas }\end{array}$ \\
\hline 17 & 87 & M & 5 & $\mathrm{~L} 2 / 3 / 4$ & $\begin{array}{l}\text { Old myocardial } \\
\text { infarction }\end{array}$ & 3 & 6.7 & 2.4 & $\mathrm{~N}$ & $\mathrm{~N}$ & Unknown & none \\
\hline 18 & 75 & $\mathrm{~F}$ & 20 & $\mathrm{~L} 3 / 4$ & & 2 & 10.4 & 16.5 & $\mathrm{~N}$ & $\mathrm{P}$ & Salmonella & Psoas \\
\hline 19 & 61 & M & 40 & L5/S & $\begin{array}{l}\text { Diabetes Mellitus, } \\
\text { decubitus }\end{array}$ & 4 & 14.6 & 22.8 & $\mathrm{P}$ & $\mathrm{P}$ & MSSA & none \\
\hline 20 & 66 & M & 21 & $\llcorner 4 / 5$ & Diabetes Mellitus & 1 & 6.3 & 3.9 & $\mathrm{~N}$ & N & Unknown & none \\
\hline Average & 68 & & 19 & & & & 12.1 & 15.0 & & & & \\
\hline
\end{tabular}

Table 1: The medical comorbidities and other information about the patients.

After saline irrigation by manual pumping through the $21 \mathrm{G}$ needle, we mainly used a broad-spectrum antibiotic, one gram of Cefazorin Sodium (CEZ; Astellas Pharma Inc. Tokyo, Japan) soaked in $20 \mathrm{ml}$ of saline, as the initial injection into the infected disc. Antibiotic was injected directly into the disc multiple times, usually twice weekly.
Patients also received antibiotic by intermittent IV. In many cases two grams of CEZ per day was administered. The drug administered to the disc was changed in response to the sensitivity of the organism and matched the IV medication. First or second generations of Cephalosporin were mainly used. Vancomycin (VCM; Shionogi AND 
Citation: Shibayama M, Li GH, Shimizu K, Miura Y, Shu N, et al. (2018) Supplemental Antibiotic Injections into the Disc Eradicate Lumbar Pyogenic Spondylodiscitis and Reduce Residual Lumbago. J Spine 7: 406. doi:10.4172/2165-7939.1000406

Page 4 of 7

Co. Ltd. Osaka, Japan) was used for cases with Methicillin-resistant Staphylococcus aureus (MRSA). Patients were not required to remain at bed rest and were allowed to walk with bracing when pain diminished. The treatment continued until inflammation subsided, as determined by relief of spine pain and decrease in levels of CRP to less than $0.5 \mathrm{mg} / \mathrm{dl}$.

\begin{tabular}{|c|c|c|c|c|c|c|c|c|c|c|}
\hline Patient & Age & Sex & $\begin{array}{l}\text { Diagnosis } \\
\text { to direct } \\
\text { Injection } \\
\text { (days) }\end{array}$ & $\begin{array}{l}\text { Number of } \\
\text { Injection }\end{array}$ & $\begin{array}{l}\text { Duration } \\
\text { of direct } \\
\text { injection } \\
\text { (days) }\end{array}$ & $\begin{array}{l}\text { Duration of } \\
\text { IV treatment }\end{array}$ & $\begin{array}{l}\text { Follow up } \\
\text { (months) }\end{array}$ & $\begin{array}{l}\text { Residual } \\
\text { lumbago }\end{array}$ & $\begin{array}{l}\text { Disc height change } \\
\text { presentation } \rightarrow 2 \mathrm{M} \rightarrow \text { last } \\
\text { follow-up }\end{array}$ & $\begin{array}{l}\text { Other } \\
\text { information }\end{array}$ \\
\hline 1 & 79 & $\mathrm{~F}$ & 3 & 3 & 20 & 41 & 49 & Excellent & $\mathrm{A} \rightarrow \mathrm{A} \rightarrow \mathrm{B}$ & \\
\hline 2 & 68 & M & 0 & 3 & 10 & 10 & 44 & Excellent & $\mathrm{B} \rightarrow \mathrm{B} \rightarrow \mathrm{B}$ & \\
\hline 3 & 60 & M & 4 & 8 & 24 & 33 & 38 & Excellent & $\mathrm{A} \rightarrow \mathrm{A} \rightarrow \mathrm{A}$ & \\
\hline 4 & 73 & M & 3 & 2 & 11 & 22 & 28 & Excellent & $\mathrm{B} \rightarrow \mathrm{B} \rightarrow \mathrm{B}$ & \\
\hline 5 & 61 & $\mathrm{~F}$ & 6 & $5+5$ & $22+20$ & $31+24$ & 23 & Good & $\mathrm{D} \rightarrow \mathrm{E} \rightarrow \mathrm{E}$ & $\begin{array}{l}\text { Relapsed } \\
\text { months later }\end{array}$ \\
\hline 6 & 78 & M & 3 & 8 & 30 & 55 & 18 & Poor & $\mathrm{A} \rightarrow \mathrm{D} \rightarrow \mathrm{D}$ & $\begin{array}{l}\text { Surgery for residual } \\
\text { lumbago }\end{array}$ \\
\hline 7 & 82 & $\mathrm{~F}$ & 4 & 12 & 41 & 51 & 9 & Excellent & $\mathrm{A} \rightarrow \mathrm{A} \rightarrow \mathrm{A}$ & \\
\hline 8 & 83 & $\mathrm{~F}$ & 3 & 4 & 9 & 23 & 9 & N/A & & $\begin{array}{l}\text { Died of cancer. } \\
\text { Infection subsided. }\end{array}$ \\
\hline 9 & 66 & M & 0 & 4 & 21 & 35 & 8 & Excellent & $A \rightarrow D \rightarrow D$ & \\
\hline 10 & 23 & M & 0 & 12 & 36 & 36 & 12 & Good & $\mathrm{A} \rightarrow \mathrm{B} \rightarrow \mathrm{B}$ & \\
\hline 11 & 67 & M & 1 & $10+6$ & $37+22$ & $48+25$ & 4 & N/A & & $\begin{array}{l}\text { Relapsed at another } \\
\text { disc, Died of cancer. } \\
\text { Infection subsided. }\end{array}$ \\
\hline 12 & 53 & M & 0 & 12 & 46 & 51 & 22 & Good & $\mathrm{B} \rightarrow \mathrm{C} \rightarrow \mathrm{C}$ & \\
\hline 13 & 62 & M & 0 & 5 & 18 & 18 & 21 & Fair & $\mathrm{C} \rightarrow \mathrm{C} \rightarrow \mathrm{C}$ & \\
\hline 14 & 82 & M & 3 & 7 & 38 & 52 & 21 & Excellent & $\mathrm{A} \rightarrow \mathrm{A} \rightarrow \mathrm{A}$ & \\
\hline 15 & 79 & $\mathrm{~F}$ & 0 & 10 & 10 & 40 & 12 & Excellent & $\mathrm{B} \rightarrow \mathrm{B} \rightarrow \mathrm{B}$ & \\
\hline 16 & 55 & M & 6 & 3 & 18 & 24 & 24 & Excellent & $\mathrm{A} \rightarrow \mathrm{A} \rightarrow \mathrm{A}$ & $\begin{array}{l}\text { Paralysis due to } \\
\text { epidural abscess, } \\
\text { posterior surgery }\end{array}$ \\
\hline 17 & 87 & M & 0 & 5 & 15 & 25 & 15 & Excellent & $\mathrm{A} \rightarrow \mathrm{B} \rightarrow \mathrm{B}$ & \\
\hline 18 & 75 & $\mathrm{~F}$ & 0 & 1 & 1 & 23 & 12 & Fair & $\mathrm{A} \rightarrow \mathrm{C} \rightarrow \mathrm{C}$ & \\
\hline 19 & 61 & M & 1 & 7 & 27 & 36 & 6 & Excellent & $\mathrm{B} \rightarrow \mathrm{C} \rightarrow \mathrm{C}$ & \\
\hline 20 & 66 & M & 6 & 4 & 20 & 17 & 12 & Excellent & $\mathrm{C} \rightarrow \mathrm{C} \rightarrow \mathrm{C}$ & \\
\hline Average & & & 2.15 & 6.8 & 24.8 & 36.8 & 18.4 & & & \\
\hline
\end{tabular}

Table 2: Summary of treatment.

There were abscesses in the psoas muscle of eight patients. Five of these patients also received injections of antibiotic into the psoas muscle under fluoroscopy in a prone position. Psoas abscesses resolved after initiation of the disc treatment and control of the infection.

There were three patients with epidural abscess. One individual needed emergent posterior decompression because of paralysis; surgery was followed by direct injection of antibiotic into the disc in addition to IV antibiotic. In the other two cases disc injection therapy was performed without surgical treatment. Table 2 demonstrates summary of treatment.

\section{Results}

According to the ASA scale, four cases each were grade 1 and 3, five were grade 4 , and seven were grade 2 . The average white blood cell count was $12600 / \mathrm{mm}^{3}$. (6300 to 22200) and the mean value of CRP was 15.0 (1.8 to 32.0$) \mathrm{mg} / \mathrm{L}$. The average time from onset to presentation to our department was 19.0 (3 to 64) days.

Direct injection started an average of 2.2 (0 to 6) days after presentation. The average duration of direct antibiotic injections into 
the disc was 24.8 days and the average number of injections was 6.8 (1 to 12). The average duration of IV treatment was 36.0 (14-63) days.

In eight of the 17 patients in whom it was performed (47\%), the causative microorganism was identified by blood culture, and in 12 of 17 patients in whom it was performed $(70.6 \%)$ an organism was isolated from the samples taken during needle aspiration biopsy. In total, 16 patients had a positive culture. The most commonly identified organism was Staphylococcus aureus (4 cases). MRSA and Streptococcus Group B were each identified in two cases. Mycobacterium tuberculosis was not found.

An abscess was found in the psoas muscle of eight patients and an epidural abscess was found in three. The epidural abscess caused severe neurological deficits in one patient (Frankel A, patient 16); this patient underwent posterior decompression surgery on the next day after presentation and then received disc injection treatment. His neurological deficits recovered fully. Except for this case, the combination of multiple disc injections of antibiotic and IV antibiotic eradicated the infection in all cases, and all abscesses disappeared without major surgery. No patients showed neurological deterioration or other adverse effects.

In one patient who received five local injections and one who received ten local injections, infection recurred within two months after the first course of treatment. The second biopsy was positive for the same microorganism in one and negative in the other. A second course of five and six local injections in combination with IV antibiotic eradicated the recurrent infections. One of these patients died of cancer within three months; the other showed no signs of relapse in a one-year follow-up period.

As for drug related adverse effect, two cases (Patient 1 and 3) showed elevation of liver enzymes after over one-month's treatment. The antibiotic treatment was ceased, however, their infection eradicated shortly after halt of the treatment.

\section{Disc height}

A

B

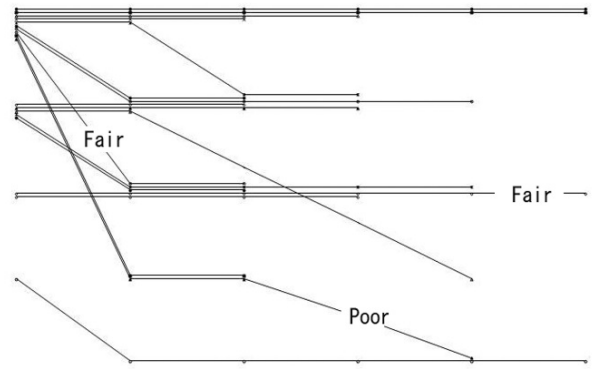

$\mathrm{E}$

\begin{tabular}{llllll}
\hline Presentation & $2 M$ & $6 M$ & $12 M$ & $2 Y$ & $3 Y$
\end{tabular}

Figure 5: Overall disc height change. A: normal height, B: half or higher, C: less than half, D: partial collision of the vertebrae, E: disappearance. Only fair and poor results are shown in the figure. Results in the other cases were excellent or good.

Excluding the two cases who died of cancer within four months after the onset of infection, the outcome for lumbago in the other 18 patients was excellent in $12(66.7 \%)$, good in three (16.7\%), fair in two $(11.1 \%)$ and poor in one (5.6\%). The poor result (patient 6) was caused by spinal deformity and spinal canal stenosis. This patient underwent posterior decompression surgery four months later.

Figure 5 shows the overall disc height change for patients with fair and poor results on the lumbago scale.

The disc height decreased in ten cases; eight of these showed a decrease in the first two months. All patients but one whose disc height was maintained or decreased slightly (one-class down) showed excellent or good outcomes for lumbago.

Figure 6 demonstrates the relationship between residual lumbago and disc height change for 18 cases during the initial two months. In this period, the disc height was maintained in 10 patients: nine of these (90\%) showed excellent results and one showed a fair result for lumbago.

\begin{tabular}{|c|c|c|c|c|c|c|}
\multicolumn{7}{|c|}{ Two months later (After treatment) } \\
\cline { 2 - 7 } & \multicolumn{1}{|c|}{} & A & B & C & D & E \\
\cline { 2 - 7 } & Normal & $\begin{array}{c}\text { Half or } \\
\text { higher }\end{array}$ & $\begin{array}{c}\text { Less than } \\
\text { half }\end{array}$ & $\begin{array}{c}\text { Partial } \\
\text { collision }\end{array}$ & Disappear \\
\hline Presentation & A & E,E,E,E,E & E, G & F & E,P & \\
\cline { 2 - 7 } & B & & E, E, E & E, G & & \\
\hline C & & & E, F & & \\
\hline D & & & & & G \\
\hline E & & & & & \\
\hline
\end{tabular}

Figure 6: Residual lumbago and initial disc height change. E: Excellent, G: Good, F: Fair, P: Poor.

In five cases the disc height moved one-class down (A to B, B to C or $\mathrm{D}$ to $\mathrm{E}$ ); two of these showed excellent results for lumbago, and results were good for three. In one patient whose disc height moved down two classes (A to $\mathrm{C}$ ), the result for lumbago was fair. Two patients showed a three-class decrease in disc height (A to D); in one of these the result for lumbago was excellent and in the other, the outcome was poor.

\section{Discussion}

The diagnosis and treatment of lumbar pyogenic vertebral osteomyelitis remain difficult, in part because increasing numbers of individuals are elderly or immuno-compromised. Standard treatment consists of strict immobilization and IV antibiotics, but invasive surgery is often necessary.

The widely accepted surgical indications $[3,4]$ are neurological deficit, significant disc and adjacent vertebral body destruction, spinal instability or developing kyphosis, psoas or epidural abscesses, intractable pain, and failed medical management. The timing of surgery is controversial. Surgery is usually selected after conservative management for one or two months has failed. The standard procedure, anterior debridement and bone grafting, is highly invasive and should not be used for a patient in poor general condition. In the current study, nine out of twenty patients (45\%) were at high risk, ASA grade 3 or 4 , because of medical comorbidities or advanced age. 
Another problem in treating lumbar pyogenic spondylodiscitis is that, even if infection subsides, prolonged conservative treatment is often followed by residual low back pain.

Variable rates for surgery are reported in the literature. Legrand et al. [5] stated that surgery is rarely needed, whereas Hadjipavlou et al. [6] and Sundararaj et al. [7] reported rates greater than $50 \%$.

Legrand et al. [5] insisted that conservative treatment alone eradicated infection in almost all cases, but the rate of residual lumbago reached $40 \%$ and functional impairment $15 \%$. Hadjipavlou et al. [6] recommended surgical treatment in part because it resulted in less residual pain (26\%) than prolonged conservative treatment (64\%).

Many authors [8-10], however, suggested that surgery is needed in approximately 25 to $30 \%$ of cases of lumbar pyogenic spondylodiscitis. In the current study, we succeeded in avoiding surgery in all but two cases $(10 \%)$, and the final outcome was extremely favorable: in 15 (83\%) out of 18 patients results were excellent or good, and we observed no functional impairment. Even in the two cases which required surgery, we were able to choose the less invasive posterior decompression.

One possible reason for the successful outcome of our strategy is that early direct treatment reduced destruction of the involved disc compared to IV treatment alone, which improved stabilization of the spine.

Nearly all patients (90\%) who maintained disc height during the initial two months showed excellent outcomes for lumbago (Figure 6). We therefore consider that preventing disc destruction in the early stage is the most important factor in reducing residual lumbago and that, if loss of disc height in the initial two months cannot be entirely prevented, keeping it to the smallest amount possible will have the best chance of reducing lumbago.

There have been several attempts to treat pyogenic spinal infections with minimally invasive surgical techniques. Since 1991, Yu et al. [11] and other authors [12-14] used percutaneous discectomy to treat pyogenic spondylodiscitis. A technique for continuous percutaneous suction drainage [15] was also developed and later modified [16]. More recently, endoscopic debridement following continuous irrigation was reported [17]. All of these methods eradicated infection in 90 to $100 \%$ of cases. The advantages of our approach are that no special instrument or technique is needed and that the procedure is safer and considerably less invasive than previously described methods.

The key element of our therapy is that the treatment should start soon after pyogenic spondylodiscitis has been diagnosed. In the previously reported minimally invasive techniques, treatment did not begin until conservative management for three weeks to two months had failed. We believe that the main focus of infection is in the disc and that early initiation of treatment of the disc is critical, because it increases the chances for isolating the causative organism [2] and preventing infection from spreading. The minimal invasiveness and absence of adverse effects justify beginning this treatment at an early stage and using multiple injections. The average number of direct antibiotic injections into the disc was 6.8 and the average duration was 24.8 days. Most patients recovered clinically within this period, but on average IV treatment continued for 10.5 days after the cessation of direct injections. The main reason for prolonged IV treatment was to provide an extra margin of safety and because CRP did not return to normal in some cases even after clinical symptoms had disappeared.
An important element of the technique is that the injection should cover the entire area of the disc. We believe that a small focus of infection in the disc is isolated from blood flow and that injecting the loculated area may open the barrier and restore the blood supply. The combination of revascularization, drainage due to needle insertion and pharmacological effects of the antibiotic helps to eradicate the disc infection.

In general, systemically administered antibiotic penetrates very poorly into the disc. For example, after intravenous Cephradine (Cephalosporine) or Flucloxacillin (Penicillin), no antibiotic was detected in discs removed during scoliosis surgery [18]. We consider that direct injection enhanced the pharmacological effect of the antibiotic and that this strategy runs little risk of creating antibioticresistant microorganisms because the same agent is used for IV and local injection.

During the procedure, we made sure to maneuver the needle tip so as to administer antibiotic to the whole disc area and to apply the injection alternately from right or left.

There is a concern that direct injection may spread infection to the epidural space or the psoas muscle, but we encountered no case in which direct injections caused epidural or psoas abscesses. We first used this technique for a patient with psoas abscess, but are now comfortable applying it to patients without psoas abscess.

Our experience includes three cases of epidural abscess. One case with severe paralysis (Frankel A) needed emergent posterior decompression surgery on the day following presentation to our hospital. We added direct antibiotic injection to IV treatment on the sixth day. His neurological deficit recovered fully after three direct injections. The result for low back pain was excellent according to Macnab's grading at the 12-month follow-up. His disc height was maintained (A to A).

Because the other two cases with epidural abscess showed no paralysis, we started direct injection treatment along with IV administration. Infection was eradicated in both cases. The low back pain of one of these patients recovered to "good" and his disc height changed from $A$ to $B$. The other case died of cancer within four months and was excluded from the lumbago study.

Our series included eight cases of psoas abscess. In five of these patients we injected antibiotic into the psoas muscle (in the prone position) in addition to injecting it directly into the disc. The technique was as follows: a $21 \mathrm{G}$ needle was placed on the transverse process, as for selective radiculography, and then advanced gradually according to the distance measured in CT image or MRI. Antibiotic injection followed aspiration of pus and saline irrigation. Infection was eradicated in all eight cases. We think that the epidural space and psoas muscle are more resistant to microorganisms than the disc because their circulation is richer, and we are confident that disc injection therapy barely spread infection to the epidural space or the psoas muscle.

Although our results show that most of the patients recovered successfully with this treatment, the study has several limitations. The number of patients was relatively small, for example, and we did not encounter cases with tuberculosis or fungus infections. Direct injection is a painful procedure for patients and an additional work for surgeons. The overall usefulness of the technique therefore remains to be established by studying more patients and different types of infection. Comparison of the present results with those produced by conservative 
Citation: Shibayama M, Li GH, Shimizu K, Miura Y, Shu N, et al. (2018) Supplemental Antibiotic Injections into the Disc Eradicate Lumbar Pyogenic Spondylodiscitis and Reduce Residual Lumbago. J Spine 7: 406. doi:10.4172/2165-7939.1000406

Page 7 of 7

treatment is important but difficult, because of large differences in patients' general condition and severity of infection. We think, however, that, in this series, our outcome was favorable both in eradicating infection and reducing residual lumbago.

\section{Conclusion}

In conclusion, repeated antibiotic injection into the infected disc provides a simple and effective treatment for eradicating lumbar pyogenic spondylodiscitis that also assists in maintaining disc height and reducing residual lumbago. It deserves broader application, especially in debilitated patients.

\section{Acknowledgement}

The authors thank Dr. Alan Tessler for preparation of manuscript.

\section{References}

1. Shibayama M, Nagahara M, Kawase G, Fujiwara K, Kawaguchi Y, et al (2010) New needle biopsy technique for lumbar pyogenic spondylodiscitis. Spine 35: 1347-1349.

2. Macnab I (1971) Negative disc exploration: An analysis of the causes of nerve root involvement in sixty-eight patients. J Bone Joint Surg 53: 891-903.

3. Emery SE, Chan DPK, Zigler JE (1989) Treatment of hematogenous pyogenic vertebral osteomyelitis with anterior debridement and primary bone grafting. Spine 14: 284-291.

4. Dimar JR, Carreon LY, Glassman SD, Campbell MJ, Hartman MJ, et al. (2004) Treatment of pyogenic osteomyelitis with anterior debridement and fusion followed by delayed posterior spinal fusion. Spine 29: 326-332.

5. Legrand E, Flipo RM, Guggenbuhl P, Masson C, Maillefert JF, et al. (2001) Management of nontuberculous infectious discitis. Treatments used in 110 patients admitted to 12 teaching hospitals in France. Joint Bone Spine 68: 504-509.

6. Hadjipavlou AG, Mader JT, Necessary J, Muffoletto AJ (2000) Hematogenous pyogenic spinal infections and their surgical management. Spine 25: 1668-1679.
7. Sundararaj GD, Babu N, Amritanand, Venkatesh K, Nithyananth M, et al. (2007) Treatment of haematogenous pyogenic vertebral osteomyelitis by single-stage anterior debridement, grafting of the defect and posterior instrumentation. J Bone Joint Surg 89: 1201-1205.

8. Rezai AR, Woo HH, Errico TJ, Cooper PR (1999) Contemporary management of spinal osteomyelitis. Neurosurgery 44: 1018-1025.

9. Butler JS, Shelly MJ, Timlin M (2006) Nontuberculous pyogenic spinal infection in adults: A 12-year experience from a tertiary referral center. Spine 31: 2695-2700.

10. O'Daly BJ, Morris SF, O'Rourke SK (2008) Long-term functional outcome in pyogenic spinal infection. Spine 33: 246-253.

11. Yu WY, Siu C, Wing PC, Schweigel J, Jetha N (1991) Percutaneous suction aspiration for osteomyelitis: Report of two cases. Spine 16: 198-202.

12. Gebhard JS, Brugman (1994) Percutanous discectomy for the treatment of bacterial discitis. Spine 19: 855-857.

13. Parker LM, McAfee PC, Fedder IL, Weis JC, Geis WP (1996) Minimally invasive surgical techniques to treat spine infections. Orthop Clin North Am 27: 183-199.

14. Haaker RG, Senkal M, Kielich T, Kramer J (1997) Percutanous lumbar discectomy in the treatment of lumbar discitis. Eur Spine J 6: 98-101.

15. Nagata K, Ohashi T, Ariyoshi M, Kyosuke S, Hiroki I, et al. (1998) Percutaneous suction aspiration and drainage for pyogenic spondylitis. Spine 23: 1600-1606.

16. Hanaoka N, Kawasaki Y, Sakai T, Nakamura T, Nanamori K, et al. (2006) Percutaneous drainage and continuous irrigation in patients with severe pyogenic spondylitis, abscess formation and remarked bone destruction. J Neurosurg Spine 4: 374-379.

17. Ito M, Abumi K, Kotani K, Kadoya K, Minami A (2007) Clinical outcome of posterolateral endoscopic surgery for pyogenic spondylodiscitis. Spine 32: 200-206.

18. Gibson M, Karpinski M, Slack R, Cowlishaw WA, Webb JK (1987) The penetration of antibiotics into the normal intervertebral disc. J Bone Joint Surg 69: 784-786. 